\title{
Uma investigação sobre avaliação e o uso de diários de aprendizagem matemática no ensino fundamental
}

\author{
Dione Baptista Ribeiro* \\ Marco Aurélio Kistemann Jr.**
}

\section{Resumo}

Este artigo tem como tema a avaliação em Matemática para que ela esteja a serviço da aprendizagem dos estudantes, por meio do uso de diários de aprendizagem. A pesquisa realizada no âmbito de um mestrado profissional, com uma abordagem qualitativa, foi realizada considerando a avaliação no Ensino Fundamental, no qual os sujeitos de pesquisa foram os estudantes do $7^{\circ}$ ano de uma escola pública. O Produto Educacional elaborado decorrente da pesquisa foi um texto dirigido a professores do Ensino Fundamental com diretrizes e sugestões sobre o ato de avaliar e regular as aprendizagens matemáticas por meio do uso de diários de aprendizagem. Os principais resultados da pesquisa apresentada nesse artigo revela que o professor deve utilizar diversas formas para avaliar, e os diários de aprendizagem auxiliam para orientar o professor com relação ao ensino, mas sobretudo para regular a aprendizagem matemática a partir da escrita discente e de suas produções de significados.

Palavras-chave: Avaliação em Matemática. Diários de Aprendizagem. Produção de Significados.

* Mestre em Educação Matemática (UFJF) e Professora na Educação Básica na rede estadual e municipal (MG).Email: pesquisadepontaufjf@gmail.com .

** Doutor em Educação Matemática (Unesp-Rio Claro-SP) e Professor no Departamento de Matemática (UFJF).Email:marco.kistemann@ufjf.edu.br . 


\title{
An investigation on the evaluation and use of mathematical learning diaries in fundamental teaching
}

\begin{abstract}
This article has as its theme the evaluation in Mathematics, so that it is at the service of student learning, through the use of learning diaries. The research carried out within a professional master's degree, with a qualitative approach, was carried out considering the evaluation in Elementary School, in which the research subjects were the students of the 7 th year of a public school. The Educational Product produced from the research was a text addressed to teachers of Elementary School with guidelines and suggestions on the act of evaluating and regulating mathematical learning through the use of learning diaries. The main result of the research presented in this article reveals that the teacher must use several ways to evaluate, and the learning diaries help to guide the teacher in relation to teaching, but above all to regulate mathematical learning from the student writing and its productions of meanings.
\end{abstract}

Keywords: Mathematics Education. Learning Diaries. Production of Meanings.

\section{Una investigación sobre evaluación y el uso de diarios de aprendizaje matemático en la enseñan- za fundamental}

\section{Resumen}

Este artículo tiene como tema la evaluación en Matemáticas para que ella esté al servicio del aprendizaje de los estudiantes, a través del uso de diarios de aprendizaje. La investigación realizada en el marco de una maestría profesional, con un abordaje cualitativo, fue realizada considerando la evaluación en la Enseñanza Fundamental, en el cual los sujetos de investigación fueron los estudiantes del $7^{\circ}$ año de una escuela pública. El Producto Educativo elaborado a raíz de la investigación fue un texto dirigido a profesores de la Enseñanza Fundamental con directrices y sugerencias sobre el acto de evaluar y regular los aprendizajes matemáticos por medio del uso de diarios de aprendizaje. El principal resultado de la investigación presentada en este artículo revela que el profesor debe utilizar diversas formas para evaluar, y los diarios de aprendizaje auxilian 
para orientar al profesor con relación a la enseñanza, pero sobre todo para regular el aprendizaje matemático a partir de la escritura discente y de sus producciones de significados.

Palabras clave: Evaluación en Matemáticas. Diarios de Aprendizaje. Producción de Significados.

\section{Introdução}

O filme americano "Escritores da Liberdade" (2007), baseado em uma história real, abordou de maneira comovente os desafios da educação, em especial num contexto socioeconômico problemático. O método de ensino e a empatia de Erin que utilizava entre outros métodos diários, resultaram, não só no sucesso acadêmico dos alunos, mas também na mudança de perspectiva de vida de cada um deles, de tal forma que ela passa a ser um fator de proteção para esses adolescentes. A ação pedagógica da professora tratada no filme é inovadora, uma vez que desperta a motivação dos alunos para expressarem em seus diários seus sentimentos, leituras, pensamentos, aprendizagens e mudar a partir do reconhecimento de que sim, eles são capazes.

Este artigo trata de um recorte da pesquisa de mestrado profissional em Educação Matemática, "Uma leitura sobre avaliação no Ensino Fundamental" (2012), realizada pela primeira autora desse artigo, inspirada na temática tratada no filme, que abordou a temática da Avaliação da aprendizagem escolar e uma forma alternativa de avaliar os estudantes. Diálogos ao longo da pesquisa piloto entre os dois autores desse artigo buscaram traçar diretrizes para a condução da pesquisa. Após a realização da pesquisa piloto tratada nesse artigo, com os devidos ajustes conduziuse a pesquisa em sua segunda parte e ao final foi apresentado o produto educacional "Uma Leitura sobre Avaliação no Ensino Fundamental" (2012). Porém, nesse artigo tratamos apenas da pesquisa piloto.

De acordo com nossa experiência, em salas de aula de ensino fundamental e médio, notamos tanto em reuniões pedagógicas quanto em cursos de formação continuada que o tema Avaliação foi e sempre é um assunto delicado. A palavra Avaliação em nosso entendimento toma variadas conotações no meio docente e escolar. Há professores que usam essa palavra e em seu discurso os significados produzidos nos possibilitam ler 
que o profissional está falando de aplicar provas, obter médias, índices e aprovar ou reprovar, a partir de um certo intervalo de notas. Esse professor, em geral é rigoroso, aplica provas individuais e busca dentro dos seus limites epistemológicos, aferir a aprendizagem dos alunos com um instrumento, a prova ou o teste, de forma individual e controlada num dado tempo. Apesar de o professor expressar-se como um avaliador, de acordo com Luckesi (2012), esse profissional exerce precisão em praticar um exame. Nesse caso, embora diga que avalia, o professor examina, pois utiliza uma única forma para verificar o que o aluno aprendeu, num processo de penalização de erros e reificação de acertos. Caso o estudante acerte mais do que erre, este atingirá um índice estipulado pelo professor e será aprovado, em contrapartida se errar mais, embora tenha estudado e saiba bastante os conteúdos lecionados, obterá um índice negativo, o que se for recorrente provocará sua reprovação.

Em nossas práticas encontramos professores que têm muita convicção no rigor que os resultados das provas fornecem de modo a dizer que se algo foi ensinado, só depende do estudante aprender. Para estes professores há duas possibilidades. Não conseguem distinguir a Avaliação de um Exame, logo praticam o processo como se fosse a mesma ação. Ou por terem se aprofundado em seus estudos sabem distinguir Avaliação e Exame e sabem, acima de tudo, que a Avaliação que é um processo, não se reduz à uma prova de verificação de acertos ou erros, como de acordo com Luckesi (2012) o exame faz bem e é preciso nessa ação.

O presente artigo tem como tema a Avaliação em Matemática. O objetivo do artigo é apresentar os resultados de uma pesquisa piloto de mestrado, destacando uma possibilidade que pode ser utilizada para a avaliação da aprendizagem matemática, os Diários de Aprendizagem. Tal avaliação pôde ser conduzida por meio dos diários, oportunizando ao professor, por meio de um produto educacional, opções para prática avaliativa que possibilitasse regular as aprendizagens discentes, como salientado por Perrenoud (1999).

Examinar, segundo uma longa tradição, baseia-se em testes escritos individuais que pretendem verificar se o aluno conseguiu reproduzir o que lhe foi ensinado, considerando um processo comunicativo que se 
pauta na transmissão de conhecimento e na obtenção de um índice. Para Baldino (1995) a concepção epistemológica que se baseia essa perspectiva de avaliação está pautada em um Ensino Tradicional Vigente (ETV). No ETV, a Matemática ensina-se falando e aprende-se ouvindo, copiando, repetindo e reproduzindo o que o professor ensinou e como ele ensinou para a geração de uma nota que dirá que o aluno é, ou não é ,capacitado num dado conteúdo.

Em nossa pesquisa de Mestrado Profissional em Educação Matemática, com tema na Avaliação em Matemática, o objetivo da investigação foi pesquisar as características de uma avaliação para que ela esteja a serviço da aprendizagem e da regulação dos saberes desses estudantes. Para tal, inicialmente, tomamos como ponto de partida apresentar os documentos oficiais e os estudos desenvolvidos sobre o tema. Cremos que para uma melhor leitura da produção de significados do estudante, precisamos que ele escreva, detalhadamente, seu raciocínio para uma questão proposta, ou que compartilhemos com ele em uma conversa e/ou um diálogo sobre o seu desenvolvimento e compreensão da questão, por exemplo.

Dentro do que propomos em nossa investigação ao longo da pesquisa, pensamos em possibilidades para produzir dados que nos norteassem na leitura da produção de significado do estudante em seus diários de aprendizagem, sem uma tecitura de juízo de valor, conforme orientado nos Parâmetros Curriculares Nacionais de Matemática do Ensino Fundamental (BRASIL, 1998).

Diversas pesquisas nos auxiliaram a entender a importância de utilizar instrumentos avaliativos alternativos, buscar investigar e analisar os erros cometidos pelos estudantes. Nesse sentido as pesquisas de Buriasco (2004), Caldeira (2004), Kistemann (2004), Ferreira (2009), Cury (2012) constituem-se de alicerces epistemológicos e metodológicos para pesquisas que se preocupem com a avaliação da aprendizagem escolar e que enriqueceram e iluminaram nossa caminhada ao longo da pesquisa piloto e da pesquisa em suas fase pós-piloto.

Nossa questão geral de investigação foi: “Quais são as características de uma avaliação em Matemática para que ela esteja a serviço da aprendizagem dos estudantes?’. Ressaltamos que esta questão descarta qualquer pos- 
sibilidade de se reduzir a avaliação a um instrumento de seleção dos aptos e, em segundo lugar, ela está orientada pelo seguinte pressuposto pedagógico, qual seja o de que o ensino deve estar submetido à regulação das aprendizagens, isto é, o foco deve estar na aprendizagem matemática do estudante.

Contudo, nas entrelinhas dessa questão de pesquisa tínhamos outras questões que poderiam auxiliar, em nossa pesquisa, a responder essa questão central. Neste artigo, apresentamos uma das questões, qual seja a que nos orientou a conduzir o estudo piloto: "Sabendo que o professor está ciente das diversas modalidades avaliativas, como utilizar os diários de aprendizagem para regular as aprendizagens, orientar-se e avaliar o conhecimento e a produção de significados dos estudantes a partir do que estes estudantes escrevem nos diários?”. Essa é a questão que buscamos abordar nesse artigo.

Nesse sentido, concordamos com D'Ambrosio (1996) quando este afirma que

a avaliação deve ser uma orientação para o professor na condução de sua prática docente e jamais um instrumento para reprovar ou reter alunos na construção de seus esquemas de conhecimento teórico e prático. Selecionar, classificar, filtrar, reprovar e aprovar indivíduos para isto ou aquilo não é missão do educador. Outros setores da sociedade devem se encarregar disso (D’AMBROSIO, 1996, p.78).

A palavra Avaliação, nos dias atuais, talvez seja a palavra mais pronunciada nos ambientes escolares e espaços educacionais governamentais, tanto no Brasil, quanto nos demais países. "Por quê?". A resposta a essa pergunta, pode querer justificar toda a preocupação que deve existir com a aprendizagem dos estudantes, entretanto, os resultados vêm mostrando que a aprendizagem fica coadjuvante, num segundo plano, sem que nos percebamos que, em geral, ambiciona-se avaliar as aprendizagens, mas acaba-se por examinar os conteúdos ensinados, o que incorre, inicialmente, em verificar se certos conteúdos foram ou não bem assimilados pelos estudantes, através de instrumentos como provas e testes.

É possível verificar que muitos professores falam, escrevem e têm até vontade de avaliar, porém falham em seus atos. Por quê? Como os professores, que desejam colocar a avaliação em Matemática na ordem do dia 
e nas suas ações cotidianas, podem começar a agir na incerteza (PERRENOUD, 1999) e começar a avaliar e incluir seus estudantes nos processos de aprendizagem? Como reduzir o exame na sala de aula e passar a avaliar e regular as aprendizagens promovendo equidade e inclusão?

Reflitamos sobre como são feitas as "avaliações” no século XXI e suas analogias com as avaliações realizadas há alguns séculos. Os professores decidem a data das mesmas, o conteúdo que será avaliado, o tempo que será gasto, quanto valerão as questões, os critérios de correção e se o aluno será promovido ou não no fim do ano. Muito diferente dos séculos passados? Em nosso entendimento não.

Concordamos com Lins (1994, p.12) quando este educador matemático diz que

não sei como você é; preciso saber. Não sei também onde você está (sei apenas que está em algum lugar); preciso saber onde você está para que eu possa ir até lá falar com você e para que possamos nos entender, e negociar um projeto no qual eu gostaria que estivesse presente a perspectiva de você ir a lugares novos.

Como professores de Matemática, precisamos saber em que lugares encontram-se nossos estudantes, que saberes eles já trazem para a sala de aula, que matemáticas da rua esses estudantes já aprenderam, para que possamos juntos praticar a avaliação dos saberes e das aprendizagens desses estudantes. Com uma avaliação processual e diagnóstica, cremos que poderemos dar continuidade ao ensino e promover a regulação constante das aprendizagens, para trilharmos novos caminhos e aprendermos novos saberes matemáticos, pois, nesse caso, a avaliação será um instrumento guia da caminhada da construção do conhecimento.

O diferencial em nossa pesquisa como um todo foi nossa postura em assumir pressupostos teóricos, trocando nossas práticas, baseadas na longa tradição em avaliar e no senso comum, por propostas e ações referenciadas teoricamente. Essa atitude, ao mesmo tempo em que permitiu um refinamento do olhar para o tema proposto permitiu também tomarmos algumas decisões.

Nos filiamos à algumas concepções de avaliação explicitadas por Lins (1999) nos seguintes termos: 
Uma noção chave em qualquer educação matemática é a de avaliação. Há muitas maneiras de se entender o que seja avaliar ou qual o propósito de se avaliar. Com relação a esse propósito podemos, por exemplo, pensar em: (A1) para saber o que está acontecendo; (A2) para saber se o que está acontecendo corresponde ao que queríamos; (A3) para selecionar as pessoas que se comportam, em algum sentido, de uma certa forma dominante e que é considerada correta.(LINS, 1999, p.76)

A leitura da citação acima nos leva a pensar que em nossa prática pedagógica deveremos ter duas coisas em mente: primeiro, que nossa ideia de avaliação deva vir, depois de fixarmos nossa concepção de educação matemática e de firmar nossos pressupostos. E segundo, que devemos deixar explícito qual é nosso propósito de avaliar. Este ponto parece ser uma conduta importante para todo professor deixar claro suas posições epistemológicas.

\section{Pressupostos Teóricos e Procedimentos Metodológicos da Pesquisa}

Na pesquisa de Kistemann Jr. (2004) já salientava-se a importância do professor no ato avaliativo processual considerando a produção de significados dos estudantes. Para educador matemático, as tarefas avaliativas podem servir de espaço comunicativo entre o professor e seus estudantes, na medida em que o professor analise as produções discentes, investigue os erros cometidos e regule as aprendizagens para que o conhecimento matemático se consolide e avance.

Nossa pesquisa, conforme proposto por Bogdan \& Biklen (1994), caracteriza-se como uma pesquisa com abordagem qualitativa. Nesse sentido, esses autores destacam que a abordagem qualitativa se caracteriza por uma flexibilidade que permite que as respostas dos sujeitos de pesquisa sejam baseadas em suas perspectivas, e não em moldes previamente elaborados. Nessa abordagem, em geral, o investigador é o único instrumento e atua com a intenção de levar os sujeitos a expressarem livremente suas opiniões sobre o assunto em questão.

Diante dessa liberdade de expressão que buscamos nos sujeitos, nossa opção teórica que orientou nossa pesquisa foi o Modelo dos Cam- 
pos Semânticos (MCS), proposto por Lins (1993, 1999), e que compartilha ideias com as teorias desenvolvidas por Vygotsky (1993, 1994), Leontiev (1984) e Nelson Goodman (1984). O MCS, nesse sentido, nos auxilia a partir das produções discentes, em suas atividades avaliativas, de modo a ler a produção de significados dos estudantes, no que estes creem e que conhecimentos estes sujeitos produzem ao serem avaliados.

Nossa identificação com o MCS se baseia no entendimento de que ele nos permitiu, como professores, entender vários aspectos dos processos de ensino e aprendizagem da Matemática. Além disso, com o MCS percebemos como o professor conhecedor das modalidades avaliativas pode vir a efetuar ações avaliativas na sala de aula, de modo a entender que significados os estudantes produzem, quando são avaliados e quando escrevem como aprenderam (ou não) um dado conteúdo ensinado. Em particular, a nosso ver, parece ser um consenso, atualmente, entre educadores matemáticos a importância de "dar voz" ao aluno e valorizar as suas produções em sala de aula.

A importância de se investigar a produção de significados é expressa por Lins (1999) quando diz: "Para mim, o aspecto central de toda aprendizagem humana - em verdade, o aspecto central de toda cognição humana - é a produção de significados”. (LINS, 2008, p.86). Seguindo nessa direção, para Lins, ensinar é sugerir modos de produção de significados e aprender é internalizar modos legítimos de produção de significados. Para este educador matemático, os conteúdos têm um papel secundário e são determinados com base no que se pretende, ou seja, nos objetivos.

Para Lins (2004) escolher um conteúdo não é escolher o que deve ser ensinado, mas, escolher o que pode ser mais útil para "exercer uma educação através da Matemática” (LINS, 2004, p.119). Na próxima secção, explicitaremos melhor como ocorreu a pesquisa piloto com os diários de aprendizagem.

\section{Pesquisa de Campo e Análises Realizadas}

Depois de fixados nossos pressupostos, propomo-nos a investigar a produção escrita dos estudantes, fazendo uma leitura dentro de dois instrumentos que elaboramos: o diário de aprendizagem e uma prova. Nes- 
se artigo apresentamos uma leitura da produção discente em diários de aprendizagem. Detalhamos ainda como se deu o teste piloto da pesquisa, e como foram utilizados os diários de aprendizagem, para que avaliássemos a aprendizagem discente e que significados eles poderiam produzir a partir do que fora ensinado.

O objetivo do teste piloto foi nos orientar sobre o uso do diário de aprendizagem como instrumento de avaliação e nos orientar com relação à regulação das aprendizagens, buscando avaliar a aprendizagem discente. No diário de aprendizagem, o objetivo foi estreitar a relação entre o estudante e o professor, descobrir o que o estudante aprendia, como aprendia e que dúvidas ele colecionava, que significados produzia, enquanto ia aprendendo os conteúdos matemáticos lecionados.

O principal interesse do diário de aprendizagem, segundo Powell \& Bairral (2006), é saber o que o aluno aprendeu (ou não), o que foi significativo para ele e as inquietações que teve. Por isso, é importante enfatizar quando Powell explicita que o uso da escrita "deve ser vista como um processo que transforma continuamente a cognição e o aprendizado de quem a produz" (POWELL \& BAIRRAL, 2006, p.11).

O teste piloto foi desenvolvido numa turma do $7^{\circ}$ ano do Ensino Fundamental de uma escola pública da rede municipal de Juiz de Fora, MG em que a primeira autora atuava como professora de Matemática. A turma era composta de 25 alunos e a opção se deu por afinidade à turma. Designaremos esta instituição escolar de escola de escola A ao longo da descrição do trabalho de campo. A escola $A$, localizada num bairro da área norte, da cidade de Juiz de Fora (MG), está localizada na zona urbana.

Os estudantes entram na escola às $7 \mathrm{~h}$ e saem às $11 \mathrm{~h} 30 \mathrm{~min}$. Todos os dias eles tem uma distribuição de cinco aulas de 50 minutos cada, ao longo da manhã. Durante a semana, os estudantes têm, no total, seis aulas de Matemática de 50 minutos cada. A identidade dos sujeitos de pesquisa foi protegida por pseudônimos e um termo de compromisso ético foi assinado pela pesquisadora, diretora da escola e responsável pelo aluno. Destacamos que os estudantes que frequentam essa escola são de família em sua maioria de baixa renda, residindo num bairro que enfrenta problemas socioeconômicos contemporâneos. Providenciamos 25 cadernos 
pequenos com pauta, de 60 folhas cada, que foram entregues a turma com algumas explicações e orientações. Pedimos que eles colocassem o nome na capa do caderno, que usassem a primeira folha para escreverem "diário de aprendizagem" e na segunda folha colocassem as instruções a seguir:

Figura 1 - Instruçès do Diário de Aprendizagem no teste piloto
Instruções para o Diário de Aprendizagem

Os diários devem incidir sobre a aprendizagem da matemática ou sobre tópicos matemáticos da aula. Quer dizer, as reflexões devem incidir sobre o que você faz, sente, descobre ou inventa. Você pode escrever sobre qualquer tópico do seu interesse. Eis algumas sugestões:

O que você aprendeu das atividades e discussões na sala de aula e das tarefas para casa?

Que sugestões você tem acerca do trabalho que a classe está fazendo ou não está sendo capaz de fazer?

Descreva descobertas que você tem feito sobre a matemática (regularidades, procedimentos etc.) ou acerca de você próprio.

Descreva o processo que você tem usado na solução de um determinado problema.

Quais são os atributos, os padrões e os relacionamentos que você tem encontrado?

Fonte: POWELL \& BAIRRAL, 2006, p.73

As instruções foram lidas conjuntamente com os estudantes participantes da pesquisas. O combinado foi que os diários ficariam conosco, ao final de todas as aulas eles escreviam e entregavam. Os diários foram lidos de duas em duas semanas e as sugestões e comentários anotados neles. No decorrer dessas duas semanas, observamos que uma aula de 50 minutos era muito pouco tempo para os alunos escreverem no diário, então combinamos de escrever nos dias de duas aulas germinadas, ou seja, uma hora e quarenta minutos de aula. Contudo, a escrita no diário poderia ser referente ao próprio dia ou ao dia anterior. Depois de duas semanas, fizemos a primeira leitura nos diários e extraímos algumas observações. As produções escritas nesse primeiro momento revelaram que alguns estudantes escreveram seu sentimento ao entender ou não a matéria, com 
muita descrição das aulas e escritas acerca das dificuldades em montar os problemas que envolvem equação. Os diálogos passam a constituir um canal de comunicação professor e estudantes, revelando as suas produções de significados acerca do que ocorria no processo de ensino e de aprendizagem.

Em alguns diários intervimos, pedindo que escrevessem, com detalhes, relatando o que entenderam (ou não), relatando se avançaram, e que detalhassem o que avançou; quando dizem que aprenderam, o que aprenderam? O processo continuou nas aulas seguintes. Ilustramos a seguir o diário de Taty e Tatha

\section{Figura 2: Diário de Taty}

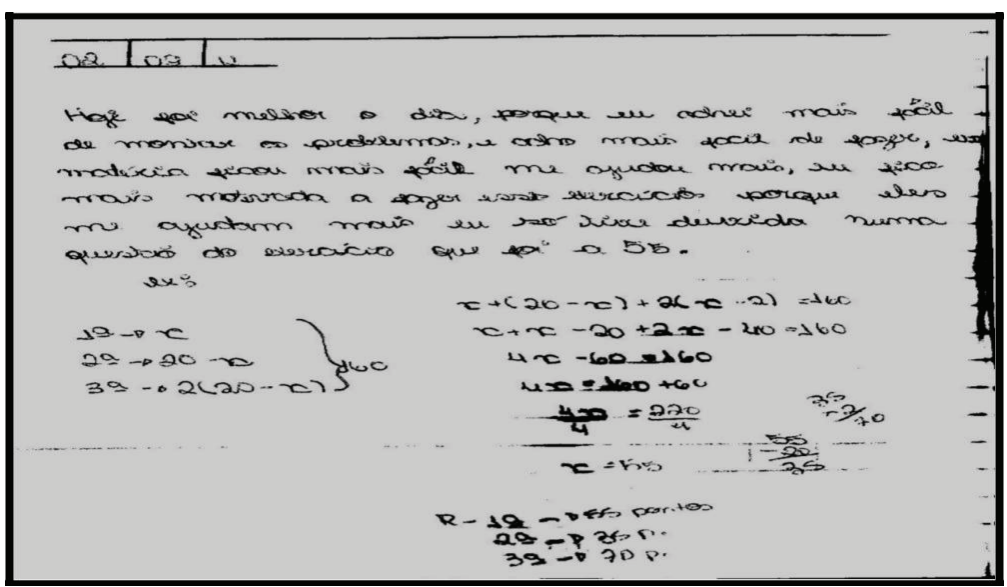

Fonte: Arquivo da Pesquisa

A figura 2 revela um dos trechos em que Taty relata para a professora como estava se sentindo com relação à aprendizagem do tema tratado, qual seja equações e incógnitas. A estudante dialoga, por meio do diário com a sua professora, explicitando sua aprendizagem e suas dúvidas. Em outro contexto a professora não tomaria conhecimento dos significados eu a estudante estaria (ou não) produzindo quando realizasse as suas tarefas. 
O diálogo que se estabelece nessas escritas pode auxiliar na evolução da aprendizagem discente, bem como na regulação das aprendizagens por meio das ações e intervenções docentes. Muitos estudantes não se sentem confortáveis em fazer perguntas durantes as aulas expositivas, por timidez ou insegurança. Por outro lado, com essa forma de avaliar com os diários, processual e com a produção escrita e autoral do estudante, o professor pode acompanhar a evolução da aprendizagem, analisar os erros cometidos e utilizar tais erros de uma forma pedagógica para que o acerto ocorra com entendimento por cada estudante.

Figura 3: Diário de Tatha

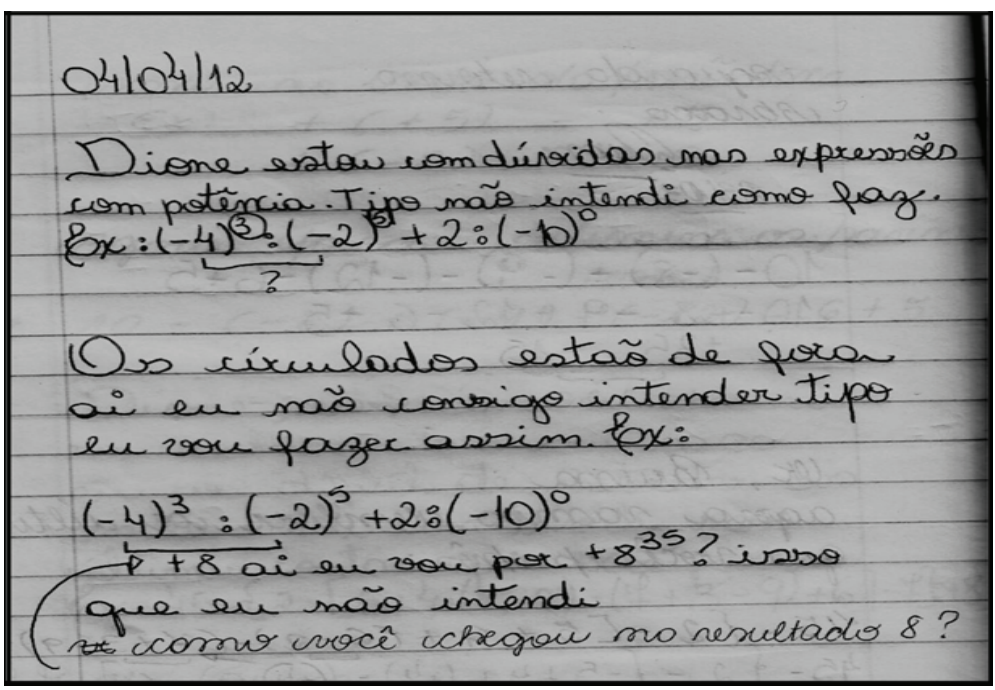

Fonte: Arquivo da Pesquisa

A figura 3 ilustra uma situação que consta do diário de Tatha envolvendo potenciação e expressão numérica, um tema em que muitos estudantes apresentam dúvidas por não estarem atualizados das propriedades operatórias. No conteúdo apresentado a estudante dialoga com a professora e percebe-se que a mesma encontra dificuldades nas operacionalizações e de como proceder para encontrar o valor da expressão. 


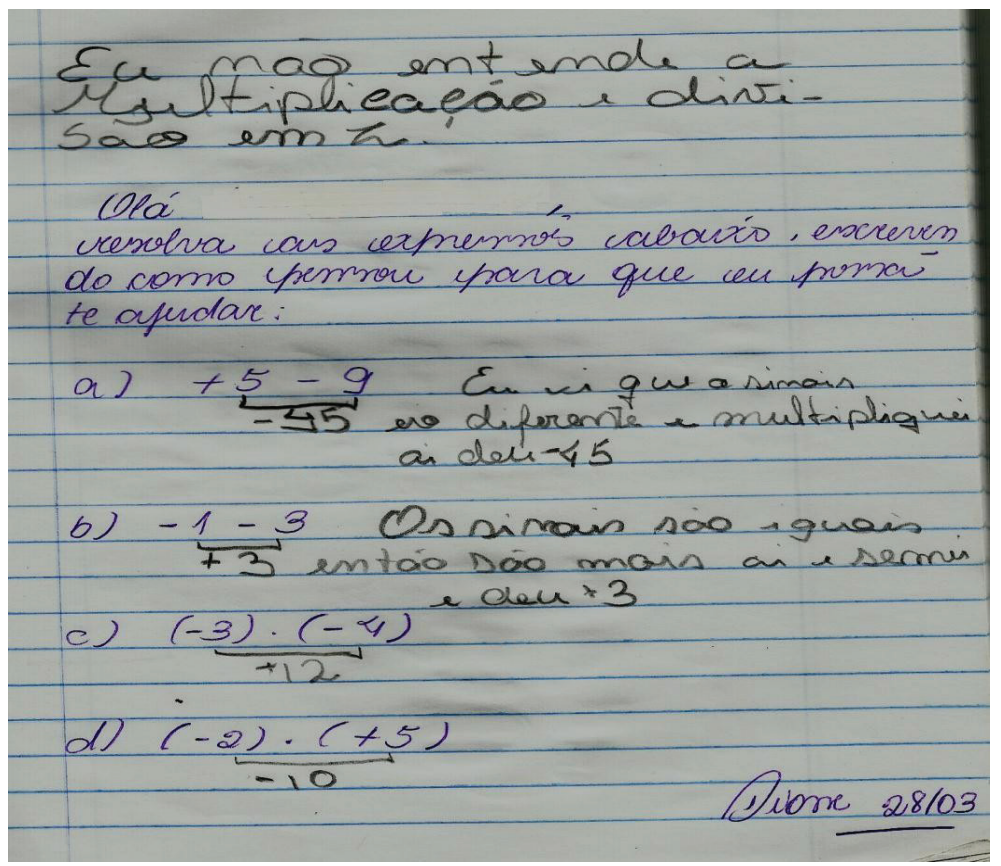

Fonte: Arquivo da Pesquisa

A figura 4 explicita um diálogo em que o estudante Biel ao não conseguir entender e produzir significados para operações com números relativos pede uma orientação à professora. Esse tema referente a números relativos têm grande incidência de erros, uma vez que muitos estudantes confundem a multiplicação e a adição ou subtração e os sinais envolvidos. Isso se deve por generalizações equivocadas, pelo ensino de macetes, ou pelos estudantes não entenderem a estrutura algébrica que rege esse conteúdo marcado muitas vezes por uma considerável abstração e estar pouco ligado ao cotidiano dos estudantes.

É nesse momento que, de acordo com o MCS proposto por Lins, o professor vai verificar onde está cognitivamente seu estudante. Que entendimentos ele já possui, que significados ele está produzindo e como conduzí-lo para chegar ao valor da expressão e aprender o conteúdo envolvido no processor. Destacamos que na mesma figura, após ler o co- 
mentário que consta no diálogo e entender as dúvidas que Tatha estava apresentando, a professora questiona Tatha sobre como um determinado resultado foi obtido. Isso numa sala de aula convencional com 40 alunos, em média, seria muito difícil, pois o professor tem que cumprir os conteúdos, "passar a matéria", buscar promover um ambiente de concentração dos estudantes, não podendo atender a cada um individualmente.

Este trabalho com o diário de aprendizagem continuou ao longo do semestre. A frequência com que líamos os diários eram de duas em duas semanas. O teste piloto foi muito relevante para nossa segunda etapa do trabalho de campo. Com ele, pensamos em reestruturar o diário de aprendizagem que usaríamos novamente na segunda etapa, já que percebemos os estudantes muito descritivos no sentido de relatar como a aula acontecia e não externavam o que aprenderam e que dúvidas ainda tinham sobre um dado objeto matemático.

Salientamos que o estudo piloto nos revelou a relevância dos diários de aprendizagem, pois os mesmos nos permitiram acompanhar em que temas os estudantes focavam mais e que significados os objetos matemáticos tinham para esses estudantes. Nesse contexto, os diários de aprendizagem revelaram, já neste teste piloto, a importância do professor utilizar diversas modalidades avaliativas para compreender e ler a produção de significados de seus estudantes. Ao optar por experimentar avaliar por meio de um diário de aprendizagem, o professor não reduz seu espaço de análise das produções de significados ao contexto da prova individual e realizada num tempo demarcado. Além de ir, gradativamente, regulando as aprendizagens, modificando suas estratégias de ensino e compreendendo como se dá a aprendizagem discente.

O diálogo entre professor e estudantes promovido, por meio dos diários de aprendizagem, nos auxiliou nessa etapa a responder à questão: "Sabendo que o professor está ciente das diversas modalidades avaliativas, como utilizar os diários de aprendizagem para regular as aprendizagens, orientar-se e avaliar o conhecimento e a produção de significados dos estudantes a partir do que estes escrevem nos diários?”.

Os dados produzidos, nesta etapa piloto, revelaram que os diários devem ser utilizados no cotidiano da sala de aula e lidos e dialogados pe- 
riodicamente, de modo que o professor possa conhecer, avaliar, regular e possibilitar, como Lins propõe, o encontro entre o professor e o estudante para que juntos possam produzir novos significados e aprimorar os saberes matemáticos. Para tal é imprescindível que o professor esteja ciente de que os diários de aprendizagem constituem-se como um das formas de entender o que os estudantes produzem de significados, ao escreverem o que foi ensinado e o que foi problematizado nas aulas.

\section{Considerações Finais}

O produto educacional, disponível em www.ufff.br/mestradoedumat/produtos, que elaboramos, a partir desta dissertação, pode servir para o professor orientar-se quanto ao uso de diários de aprendizagem e conhecer sobre as diversas formas de avaliação e suas idiossincrasias. Com isso esperamos que o professor tenha um vasto material de estudo para orientar a reflexão e caminhos para sua prática avaliativa em sala de aula. Neste produto encontram-se as características de uma avaliação e também a importância do professor assumir pressupostos durante a sua prática.

Nesse comenos, avaliar vai além do ato de examinar, como proposto por Luckesi (2012). Com a utilização dos diários de aprendizagem isso será possível, pois o professor acompanhará a evolução dos significados produzidos por seus estudantes e poderá situar onde esses estudantes estão para poder (re)encontrá-los e juntos.

Como proposto por Lins (1994), os estudantes poderão trilhar novos caminhos e produzir juntos novos saberes matemáticos que, ao serem escritos nos diários de aprendizagem, poderão auxiliar o professor a avaliar o que este sujeitos estão aprendendo e como estão aprendendo. Nesse contexto, cremos que o estudante poderá ser avaliado em seus saberes e nos significados que produz, a partir dos textos, tarefas e atividades apresentadas pelo professor.

Por fim, entendemos que cabe aos professores de Matemática, em particular, conhecerem e experimentarem novas formas de avaliar a aprendizagem de seus estudantes.. Avaliar e regular as aprendizagens, conforme nos esclarece Perrenoud (1999) constitui-se como uma das principais competências para a atuação do professor na sala de aula do século XXI, 
na busca por um ensino de qualidade, mas sobretudo uma aprendizagem matemática que promova a autonomia discente.

\section{Referências}

ALLAL, Linda. Estratégias de avaliação formativa: concepções psicopedagógicas e modalidades de aplicação: In: Avaliação num ensino diferenciado - Atas do colóquio realizado na Univ. de Genebra, março 1978. Coimbra: Livraria Almedina, 1986, p. 175-209.

BALDINO, Roberto Ribeiro. Assimilação Solidária. Grupo de Pesquisa-Ação em Educação Matemática - GPA, UNES:, Rio Claro, 1995. (Apostila)

BOGDAN, Robert; BIKLEN, Sari. Investigação Qualitativa em Educação. Uma introdução à teoria e aos métodos. Portugal: Porto Editora, 1994.

BRASIL. Secretaria de Educação Fundamental. Parâmetros curriculares nacionais - Matemática: Introdução. $5^{a}$ a 8 a séries. Brasília: MEC / SEF, 1998.

BURIASCO, Regina. Análise da Produção Escrita: a busca do conhecimento escondido. In: ENCONTRO NACIONAL DE DIDÁTICA E PRÁTICA DE ENSINO (Endipe), 7., 2004, Curitiba. Anais... Curitiba: Editora Universitária Champagnat, 2004.

CALDEIRA, Ana Cristina Muscas. Avaliação da aprendizagem em meios digitais: novos contextos, São Paulo, abril 2004.

CURY, Helena Noronha. Pesquisas em ensino de ciências e matemática, relacionadas com erros: uma investigação sobre seus objetivos. Educação Matemática Pesquisa, São Paulo, v.14, n.2, p. 237-256, 2012.

D’AMBROSIO, U. Educação matemática: da teoria à prática. Campinas: Papirus, 1996.

RIBEIRO, DIONE BAPTISTA. Uma leitura sobre avaliação no Ensino Fundamental. 2012. 125p. Dissertação (Programa de Mestrado Profissional em Educação Matemática)-Universidade Federal de Juiz de Fora (UFJF), Juiz de Fora, 2012.

FERREIRA, P. E. A. Análise da produção escrita de professores da Educação Básica em questões não-rotineiras de matemática. 2009. 166p. Dissertação (Programa de Pós-Graduação em Ensino de Ciências e Educação Matemática) - Universidade Estadual de Londrina, Londrina, 2009. 
GOODMAN, Nelson. Of mind and other matters. London: Harvard University Press, 1984.

HOFFMANN, Jussara. Avaliação Mediadora: Uma prática em construção da pré-escola à universidade. Porto Alegre: Editora Mediação, 2001. 197p.

A avaliação: limites e possibilidades. Disponível em: $<$ http:// edicoessm.com.br/gestor_escolar_fundamentos/avaliacao/apoio.pdf>. Acesso em: 01 de agosto de 2012.

Avaliar para promover: as setas do caminho. Porto Alegre: Editora Mediação, 2002. 219p.

KISTEMANN JR., Marco Aurélio. O Erro e a Tarefa Avaliativa em Matemática: uma Abordagem Qualitativa. Dissertação de Mestrado, Rio de Janeiro - RJ, 2004.

LEONTIEV, A. N. Actividad, conciencia y personalidad. Mexico: Cartago, 1984.

LINS, Romulo Campos. Por que discutir teoria do conhecimento é relevante para a Educação Matemática. In: Bicudo, M. A. V. (org). Pesquisa em Educação Matemática: concepções e perspectivas. São Paulo: Editora da UNESP, 1999, p. 75-97.

A diferença como oportunidade para aprender. In: XIV

ENDIPE, 2008, Porto Alegre. Trajetórias e processos de ensinar e aprender: sujeitos, currículos e culturas. Porto Alegre: Edi PUCRS, v.3. p. 530-550, 2008.

LUCKESI, C.C. Avaliação da Aprendizagem Escolar - Estudos e Proposições. 22. ed. Cortez Editora, 2011.

MONTEIRO, Eliziê Franz de Castro. Práticas Avaliativas em Matemática na Educação de Jovens e Adultos: um estudo de caso de uma escola da Rede Municipal de Belo Horizonte. Dissertação de Mestrado, Ouro Preto - MG, 2010.

PERRENOUD, Philippe. Avaliação da excelência regulação das aprendizagens: entre duas lógicas. Porto Alegre: Artmed, 1999.

POWELL, Arthur; BAIRRAL, Marcelo. A escrita e o pensamento matemático: interações e potencialidades. Campinas, SP: Papirus, 2006 - (Coleção Perspectivas em Educação Matemática).

RABELO, Edmar Henrique. Avaliação: novos tempos, novas práticas. 8. ed. Petrópolis: Vozes, 2009. 